Voureka, Amalia \& Ogilvie, A. C. (1952). J. gen. Microbiol. 7, 48-53

\title{
Toxin Production in Two Strains of Staphylococcus and their Variants
}

\author{
By AMALIA VOUREKA and A. C. OGILVIE \\ The Wright-Fleming Institute of Microbiology, St Mary's Hospital \\ Medical School, London, W. 2
}

SUMMARY: Two mouse virulent strains of Staphylococcus aureus and their avirulent variants were tested for their resistance to the bactericidal power of fresh human blood and for toxin production.

The variants were much more easily killed by fresh blood than the parent strains and had lost the ability to produce $\alpha$-haemolysin, dermonecrotic toxin and leucocidin.

The Panton-Valentine leucocidin test was supplemented by two others that gave more reliable results, one depending on direct observation of leucocytes emigrated from a clot on to the surface of a slide, the other on the destruction of bactericidal power of the leucocytes.

Avirulent variants obtained from a virulent strain of Staphylococcus aureus by exposure to noxious agents for a sublethal time have been described (Voureka, 1952). In these variants the loss of virulence was always accompanied by loss of certain characters connected with virulence such as coagulase production, mannitol fermentation and gelatin liquefaction.

It was of interest to investigate other characters associated with virulence in parent and variant strains. Resistance to the bactericidal effect of whole blood, haemolysis, dermonecrotic effect and leucocidin were tested.

Two strains of staphylococci, A and B, were used. The parent strain A, originally obtained from a human infection, had been kept on artificial media for 4 years; and at the time of its use was rough in colonial appearance although highly virulent for mice. Of its variants A III was obtained by exposing $\mathbf{A}$ to $20 \mu \mathrm{g}$. chloramphenicol $/ \mathrm{ml}$. for $24 \mathrm{hr}$. in vitro. A VIII was similarly obtained using 50 $\mathrm{g}$. terramycin $/ \mathrm{ml}$. (Voureka, 1952). A 10 was obtained from the heart blood of a mouse infected intraperitoneally with $A$ and given $2.5 \mathrm{mg}$. terramycin intravenously $12 \mathrm{hr}$. later.

Parent strain B was freshly isolated from a human infection and was smooth and mouse virulent. Its variant B 4 was obtained in a similar way to A 10 .

\section{Resistance to bactericidal effect of blood}

Organisms vary greatly in their resistance to the bactericidal action of fresh human blood, and virulent strains usually are much more resistant than avirulent strains. Resistance to bactericidal power was tested by the slide cell technique (Wright, 1923). Dilutions of $16 \mathrm{hr}$. broth cultures of the staphylococcal strains were made and a sample of each dilution was taken for viable counting in serum in slide cells. At the same time $25 \mathrm{cu} . \mathrm{mm}$. of normal human blood and 5 cu.mm. of each culture dilution were mixed and run into slide cells. After overnight incubation at $37^{\circ}$ the number of colonies developing 
in the slide cells were counted. The approximate number of staphylococci added to each slide cell was estimated from the viable count. The results obtained are shown in Table 1. The greater bactericidal power of the blood for the variants than for the parent strains is clearly demonstrated.

Table 1. Bactericidal effect of blood on staphylococcal strains

$\begin{array}{ccc}\begin{array}{c}\text { Approximate } \\ \text { Strain of }\end{array} & \begin{array}{c}\text { Number } \\ \text { number of } \\ \text { staphylococei } \\ \text { added }\end{array} & \begin{array}{c}\text { develonies } \\ \text { slide cells }\end{array} \\ \text { A } & 2600 & 369 \\ \text { AIII } & 2900 & 12 \\ \text { A VIII } & 6500 & 50 \\ \text { A 10 } & 2900 & 22 \\ \text { B } & 2250 & 246 \\ \text { B4 } & 2500 & 7\end{array}$

Toxin-antitoxin precipitation in solid media

The method used was similar to that described by Elek (1948). A $\frac{1}{4}$ in. gutter in an agar plate was filled with agar containing a high concentration of staphylococcal antitoxin (refined staphylococcus antitoxin globulins, Burroughs Wellcome). Streaks of the staphylococei were made at right angles to this gutter and the plate incubated at $37^{\circ}$ in $20 \% \mathrm{CO}_{2}$ for $48 \mathrm{hr}$. or longer. Lines of precipitate were formed (Pl. 1, fig. 1). They are numerous and clearly seen near the streaks of A and B. A 10, AVIII and B4 each showed two very indistinct lines which are scarcely visible in the photograph. A III formed one very poorly visible line.

\section{Methods of obtaining and testing toxins}

Haemolysin, dermonecrotic factor and leucocidin. The organisms were seeded on plates of $0.5 \%$ nutrient agar. These were incubated at $37^{\circ}$ in $20 \% \mathrm{CO}_{2}$. An uninoculated plate of $0.5 \%$ agar treated in the same way served as a control.

After incubation the agar was centrifuged. The supernatant from 6-day cultures was used directly for haemolysin and dermonecrotic toxin tests, and that from $24 \mathrm{hr}$. cultures was filtered through a collodion membrane to ensure sterility in tests for leucocidin. Parent and variant strains showed good growth in all cases.

Haemolysins. (a) Tube tests. The supernatant was used unheated and after heating to $55^{\circ}$ for $30 \mathrm{~min}$. to destroy $\alpha$-haemolysin and leave about one-half of any $\beta$-haemolytic activity intact (Llewellyn Smith \& Price, 1938a). Serial dilutions commencing at $1 / 5$ of each of the supernatants in $20 \%$ broth saline were made in duplicate rows of tubes. Equal volumes of $2 \%$ washed rabbit corpuscles and of $2 \%$ sheep corpuseles were added to each tube of the first and second rows respectively. Readings were made after incubation for $\mathbf{1 ~ h r}$. in a $37^{\circ}$ water-bath and again after leaving in the refrigerator at $4^{\circ}$ overnight. The haemolytic titre was recorded as the reciprocal of the highest dilution producing distinct naked eye haemolysis. Table 2 shows the results obtained 
with the parent strains. None of the variants showed any haemolysin by this method.

(b) Tests with antitoxin in blood agar plates. Plates of $2 \%$ rabbit and $2 \%$ sheep blood agar were used. A circular well about $\frac{3}{4}$ in. in diameter was cut out of the centre of the agar and was filled with agar containing a high concentration of the staphylococcus antitoxin. Radial streaks of the staphylococci were made radiating from the edge of the antitoxin well. After incubation at $37^{\circ}$ in $20 \% \mathrm{CO}_{2}$ for $48 \mathrm{hr}$. the plates were examined for haemolysis. The plates were then left at $4^{\circ}$ for $16 \mathrm{hr}$. and re-examined.

Table 2. Tube tests for haemolysin on parent strains

\begin{tabular}{|c|c|c|c|c|c|c|c|c|}
\hline & & & mu & tre of $h$ & olysi & & & \\
\hline & & $2 \% \mathrm{rabl}$ & it cells & & & $2 \%$ shee & $p$ cells & \\
\hline & $\begin{array}{l}\text { Un } \\
\text { sup }\end{array}$ & meated & $\begin{array}{r}\text { H } \\
\text { sup }\end{array}$ & eated & $\begin{array}{l}\text { Ur } \\
\text { sup }\end{array}$ & rnatant & $\begin{array}{r}\text { H } \\
\text { supe }\end{array}$ & enated \\
\hline Strain & $\begin{array}{l}1 \mathrm{hr} . \\
37^{\circ}\end{array}$ & $\begin{array}{l}1 \mathrm{hr} ., 37^{\circ} \\
16 \mathrm{hr} ., 4^{\circ}\end{array}$ & $1 \mathrm{hr} .$, & $\begin{array}{c}1 \mathrm{hr} ., 37^{\circ} \\
16 \mathrm{hr} ., 4^{\circ}\end{array}$ & $1 \mathrm{hr} .$, & $\begin{array}{c}1 \mathrm{hr} ., 37^{\circ} ; \\
16 \mathrm{hr} ., 4^{\circ}\end{array}$ & $1 \mathrm{hr}$. & $\begin{array}{l}1 \mathrm{hr} ., 37^{\circ} ; \\
16 \mathrm{hr} .4^{\circ}\end{array}$ \\
\hline $\mathbf{A}$ & 40 & 160 & 0 & 10 & 10 & 40 & 0 & 0 \\
\hline B & 10 & 20 & 0 & $\mathbf{0}$ & 0 & 10 & 0 & 0 \\
\hline
\end{tabular}

In both rabbit and sheep blood agar plates strains A and B produced a wide zone of lysis with hazy margins ( $\alpha$-haemolysis). This haemolysis was inhibited by the antitoxin for some distance and a narrower zone of sharply defined lysis was thus disclosed which extended uninhibited right up to the antitoxin well.

The variants produced narrow zones of lysis with sharp edges, that of A VIII being the narrowest. The haemolysis produced by all the variants was not inhibited by the antitoxin.

There was no obvious difference between the lysis observed on sheep and on rabbit blood agar with any strain, nor was there any change after refrigeration.

From the observations on blood plates we conclude that strains $\mathbf{A}$ and $\mathbf{B}$ produced $\alpha$-haemolysin and another lysin, not neutralized by our antitoxin, whose characters are those of $\alpha_{2}$ - or $\gamma$-haemolysins (Morgan \& Graydon,1936; Llewellyn Smith \& Price, 1938b). All the variants had lost the ability to produce $\alpha$-toxin, although still producing a lysin similar to the second haemolysin produced by the parent strains.

Dermonecrotic effect. Intradermal injection of $0.2 \mathrm{ml}$. of each supernatant was made into the depilated back of a rabbit. Results were read after $48 \mathrm{hr}$. Necrosis of the skin was widespread with supernatants from A and B. A10 showed a marked zone of erythema with possible early necrosis, A III moderate erythema and B4 only slight erythema. The control fluid produced no change.

Leucocidin. The accepted method is that described by Panton \& Valentine (1932). In addition two other methods were devised.

(1) Panton and Valentine method. Incubation of washed blood cells with filtrates from the staphylococcal cultures was carried out for 1, 2, 4 and $24 \mathrm{hr}$. Films were stained with Leishman stain and examined for the presence of 
polymorphonuclear (P.M.N.) leucocytes. U'sing this technique, results were equivocal with the shorter times of incubation. Filtrates from the parent strains $A$ and B after $4 \mathrm{hr}$. incubation with washed cells caused changes in the P.M.N. leucocytes but these were only indisputable after $24 \mathrm{hr}$. incubation. Filtrates from the variants showed no leucocidal activity, the appearances being the same as those in which the control fluid had been used. It may be that the filtrates used contained too little leucocidin for its action to be detectable in less than $24 \mathrm{hr}$. by this method.

(2) Leucocyte emigration method. Emigration on the surface of glass slides (Wright, 1918) was used to obtain a concentrated collection of leucocytes. Three paraffin framed cells were made on each of several slides. Three drops of fresh unclotted blood were dropped into each cell and incubated for $\frac{1}{2} \mathrm{hr}$. in a moist chamber to allow emigration of the P.M.x. leucocytes on to the surface of the slide. The clot was then thrown off. The slides, with emigrated leucocytes, were gently washed several times with the fluid to be tested. Three drops of the fluid were then dropped on to the cells which were reincubated in the moist chamber. A set of five slides for each strain and for the control was used. After 1, 2, 3, 4 and $24 \mathrm{hr}$. one slide from each set was taken out, the fluid was thrown off and the slide was allowed to dry. The cells were stained with Leishman stain and examined microscopically.

The leucocytes on the slides which had been in contact with supernatants from the control and from the variants at all times showed no differences. The supernatant from strain A and, to a lesser extent, from strain B caused progressive damage to the P.M.N. leucocytes which could readily be followed. After incubation for $1 \mathrm{hr}$. the nuclei were swollen and seemed less dense and clearly defined than normal. After 2, 3 and $4 \mathrm{hr}$. the damage was very advanced, the leucocytes were swollen and their nuclear material appeared to be scattered all over the cells. After $24 \mathrm{hr}$. most cells were destroyed leaving only debris and 'ghost cells' (PI. 1, fig. 2).

(3) Slide cell method. The preceding methods depend on direct observation of morphological changes occurring in the P.M.N. leucocytes. It has been shown that the bactericidal power of the blood is destroyed by removal or destruction of leucocytes. Hence we thought that leucocidin might be detected by an effect on the bactericidal power of blood. For this slide cells were used with enterococcus as the test organism, since this is readily destroyed by normal P.M.N. lcucocytes, and, since the organism used was hacmolytic, growth was easy to observe. Blood from a normal subject was centrifuged, the serum removed and kept in a sterile tube. The deposited blood cells were washed three times in physiological saline. Equal volumes of sterile staphylococcal filtrate and washed blood cells were mixed in tubes and incubated at $37^{\circ}$ for $2 \frac{1}{2} \mathrm{hr}$. with periodic shaking to keep the contents mixed. At the end of this time 25 cu.mm. of this mixture, $25 \mathrm{cu} . \mathrm{mm}$. of the sterile serum and 5 cu.mm. of a $1: 1000$ dilution of an overnight broth culture of enterococci were mixed in a sterile pipette. These mixtures were introduced into slide cells, which were then sealed. After incubation at $37^{\circ}$ overnight the slide cells were examined and the number of colonies developing observed. 
The results (Pl. 1, fig. 3) show that maximum growth occurred in mixtures containing filtrates from A and B. Filtrates from A 10 were slightly active, from B 4 very slightly active, from AIII inactive. Hence filtrates from the parent strains contained a factor which destroyed the bactericidal power of human blood, whereas the variants produced this factor in small amounts only or not at all.

In order to compare the sensitivity of this method with that of direct methods for measuring leucocidin, filtrate from strain $\mathbf{A}$ was used at various dilutions. Pl. 1, fig. 4 shows that the bactericidal power of blood was markedly reduced at a dilution of $1 / 4$ but not at $1 / 8$. Using the same filtrate Panton $\&$ Valentine's method and the emigration method showed definite destruction of a large number of P.M.N. leucocytes also at a dilution of $1 / 4$ but not at $1 / 8$.

\section{DISCLSSION}

With all the tests used, differences between the parent strains and their avirulent variants were observed which were consistent with the loss of virulence. The number of strains used is too small to draw general conclusions. However, our comparisons between avirulent variants and their virulent parents further supports the generally accepted belief that $\alpha$-haemolysin, dermonecrotic factor and leucocidin are closely related to virulence.

Panton \& Valentine's method of testing for leucocidin was found to be simple and gave definite results especially after $24 \mathrm{hr}$. incubation. With the weak leucocidin filtrates we were using the P.M.N. emigration method gave quicker results and allowed the demonstration of progressive destruction of the leucocytes.

The ability of staphylococcal filtrates to destroy or diminish the bactericidal power of washed human blood cells, if shown by later work to be due to leucocidin, may allow use of the slide cell method for its estimation. If this is the case, this method may be the one of choice because of its objectivity which is independent of individual interpretation of what constitutes significant leucocyte destruction.

We wish to thank Prof. Sir Alexander Fleming for his helpful encouragement and advice.

\section{REFERENCES}

Elek, S. D. (1948). The recognition of toxicogenic bacteria strains in vitro. Brit. med. J. i, 493.

Morgan, F. G. \& Graydon, J. J. (1936). Toxins of the Staphylococcus with special reference to the estimation of potency. J. Path. Bact. 43, 385.

Panton, P. N. \& Valentine, F. C. O. (1932). Staphylococcal Toxin. Lancet, i, 506.

Smith, M. Llewellyn \& Price, S. A. (1938a). Staphylococcus $\beta$ Haemolysin. J. Path. Bact. 47, 361.

Smith, M. Llewellyn \& Price, S. A. (1938b). Staphylococcus $\gamma$ Haemolysin. J. Path. Bact. 47, 379.

Voureka, A. (1952). Induced variations in a penicillin resistant staphylococcus. J. gen. Microbiol. 6, 352.

Wright, A. E. (1918). New methods for the study of emigration and of the bactericidal effects exerted in the wound by leucocytes. Lancet, i, 129.

Wright, A. E. (1923). New principles in therapeutic inoculation. Lancet, i, 365, 417, 473. 
Journal of General Microbiology, Vol. 7, Nos. $1 \& 2$

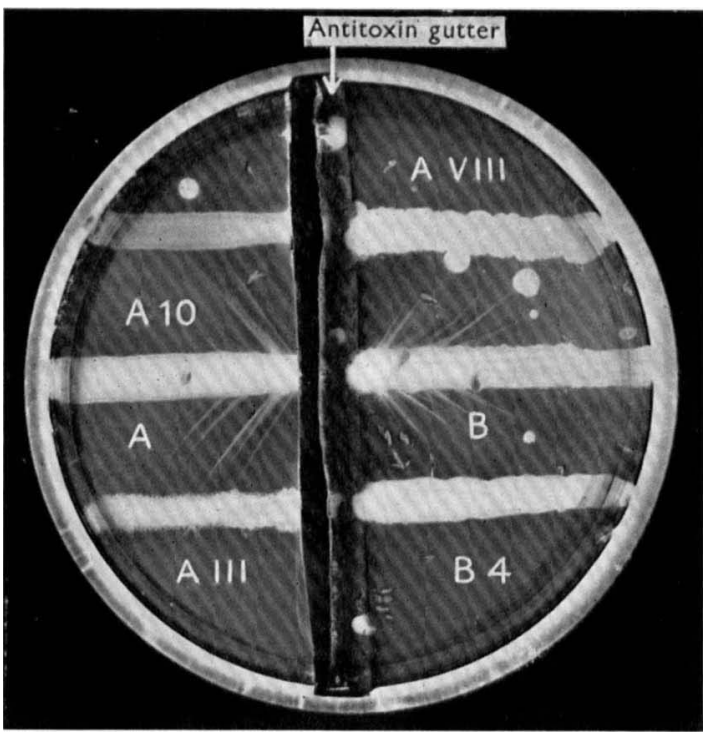

Fig. 1
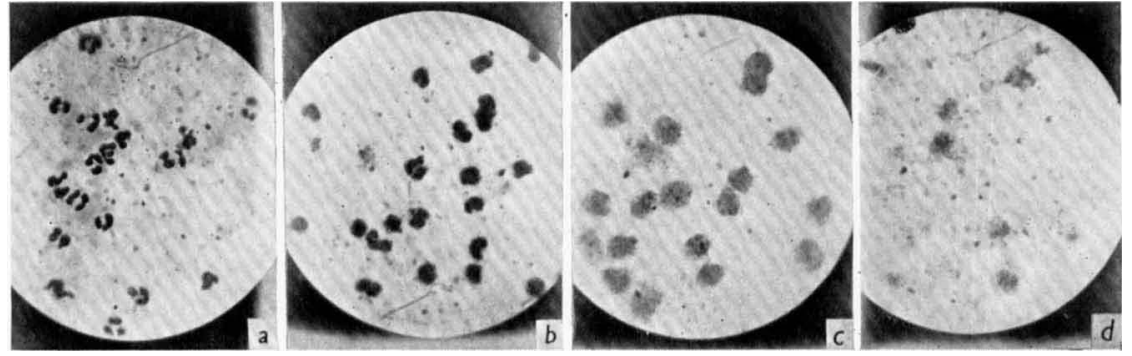

Fig. 2

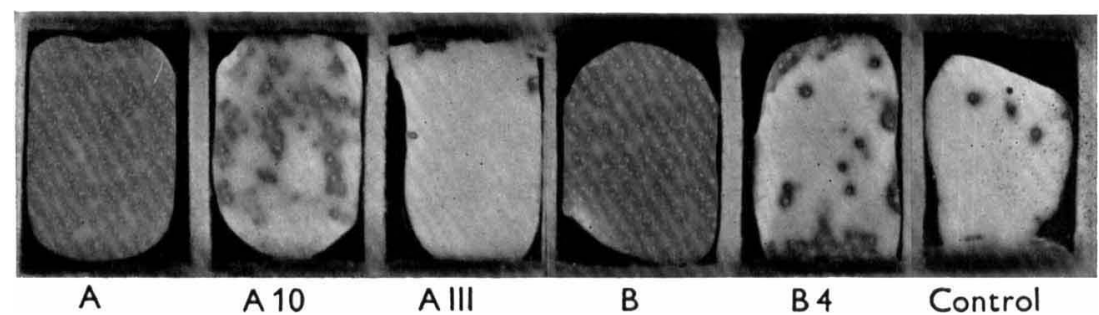

Fig. 3

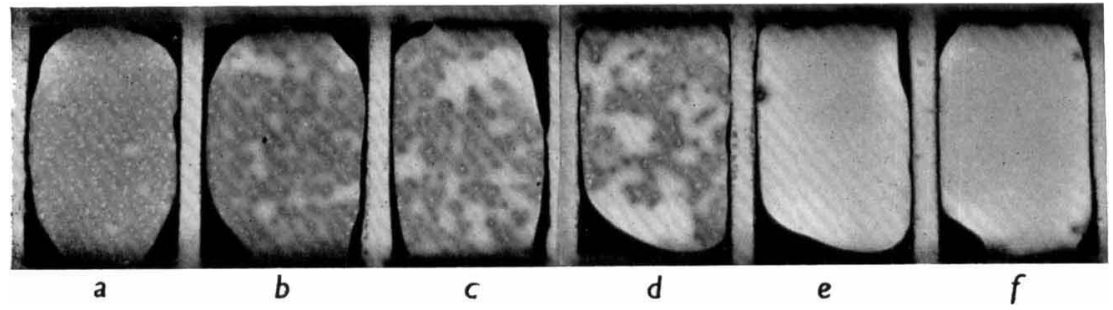

Fig. 4

Amalia Voureka \& A. C. Ogilvin-Toxin probcction in stapifylococcal variants. Plate 1 